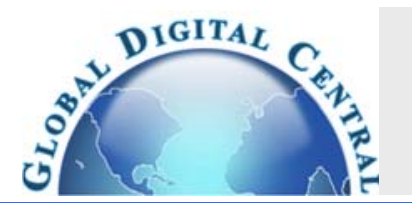

Frontiers in Heat and Mass Transfer

Available at www.ThermalFluidsCentral.org

\title{
EFFECT OF ELASTIC DEFORMATION ON NANO-SECOND GRADE FLUID FLOW OVER A STRETCHING SURFACE
}

\author{
R. Kalaivanan ${ }^{\mathrm{a}}$, B. Ganga ${ }^{\mathrm{b}}$, N. Vishnu Ganesh ${ }^{\mathrm{c}}$ and A.K. Abdul Hakeem ${ }^{\mathrm{a}}$,** \\ ${ }^{a}$ Department of Mathematics, Sri Ramakrishna Mission Vidyalaya College of Arts and Science, Coimbatore - 641 020, India. \\ ${ }^{b}$ Department of Mathematics, Providence College for Women, Coonoor - 643 104, India. \\ ${ }^{c}$ Department of Mathematics, Ramakrishna Mission Vivekananda College, Chennai- 600 004, India.
}

\begin{abstract}
The main aim of the present article is to investigate the elastic deformation effects on the boundary layer flow of an incompressible second grade twophase nanofluid model over a stretching surface in the presence of suction and partial slip boundary condition. The second grade nanofluid model with elastic deformation effects is investigated for the first time. The combined effects of elastic deformation, Brownian motion and thermophoresis are also analyzed for the first time. To analyses the heat transfer, heat and mass flux boundary conditions are considered. The governing boundary layer nonlinear partial differential equations are converted into a set of ordinary differential equations by means of similarity transformations. Numerical solutions are obtained using fourth order Runge-Kutta method together with shooting method. The combined effects of elastic deformation with other physical parameters on thermal field, solid volume fraction, skin friction coefficient, local Nusselt number and local Sherwood number are discussed graphically. It is found that the elastic deformation parameter enhances the local Nusselt number and decreases the local Sherwood number.
\end{abstract}

Keywords: Elastic Deformation, Heat Flux, Mass Flux, Slip Flow, Second Grade Nanofluid.

\section{INTRODUCTION}

During the recent decades, convective heat transfer of nanofluids is a hot topic of academic and industrial research due to its various applications in industrial processes such as thermal heating, power generation and chemical processing etc. The nanofluid is a new kind of fluid introduced by Choi (1995) and he suggested an innovative way to improve the heat transfer of conventional fluids by suspending nano sized solid and oxide nanoparticles. Now a day, nanofluids have been commonly used in many scientific and industrial applications because of its stability and free from erosion, sedimentation and additional pressure drop.

Thermophoresis plays a vital role in many industrial applications, such as in aerosol collection, nuclear reactor safety and removing small particles from gas streams. The small particles experience a force in the direction of the temperature gradient when suspended in a liquid with a temperature gradient. The velocity of these particles which drives it from hot surface region to the cold surface region is called thermophoretic velocity and the force experienced by the these suspended particle due to the temperature gradient is called thermophoretic force. The concept of thermophoretic velocity and thermophoretic force was first observed by John Tyndall in 1870. The random movement of the suspended particles in a fluid is known as Brownian motion. In nanofluids, Brownian motion of nanoparticles is a major key mechanism governing the thermal performance of nanoparticle in basefluids at the molecular and nanoscale level. Much attention has been given to analysis the nanofluid flow in different geometrics (Sheikholeslami 2014 ; M.M. Rashidi et al. 2014; Abolbashari et al. 2014; Sheikholeslami and Rashidi 2015; Sheikholeslami et al. 2015; Govindaraju et al. 2017; Sheikholeslami 2017a ; Sheikholeslami 2017b ; Sheikholeslami 2017c ; Sheikholeslami 2017d ; Sheikholeslami and Rokni 2017a; Sheikholeslami and Rokni 2017b; Sheikholeslami and Shehzad 2017a; Sheikholeslami et al. 2017a). Abdul Hakeem et al. (2015) analyzed the magnetic field effect on second order slip flow of nanofluid over a stretching/shrinking sheet. Sheikholeslami (2017e) studied the Lattice Boltzmann method simulation for MHD non-Darcy nanofluid free convection. Sheikholeslami and Bhatti (2017) discussed active method for nanofluid heat transfer enhancement by means of EHD. Sheikholeslami and Shamlooei (2017) studied the $\mathrm{Fe}_{3} \mathrm{O}_{4}-\mathrm{H}_{2} \mathrm{O}$ nanofluid natural convection in presence of thermal radiation. Magnetohydrodynamic nanofluid convection in a porous enclosure considering heat flux boundary condition was discussed by Sheikholeslami and Shehzad (2017b). Sheikholeslami et al. (2017b) investigated the numerical study for external magnetic source influence on water based nanofluid convective heat transfer.

Buongiorno (2005) developed a homogenous equilibrium model which includes seven slip mechanisms such as Brownian diffusion, thermophoresis, inertia, diffusiophoresis, magnus effect, fluid drainage and gravity that could produce a relative velocity between the nanoparticles and the base fluid. Recently, Goyal and Bhargava (2013) introduced viscoelastic fluid based nanofluid model and investigated the MHD, slip and heat source/sink effects. The same author's (2014) studied the slip effects on boundary layer flow on second grade nanofluid over a stretching sheet. Shit et al. (2015) analyzed convective hest transfer and MHD nanofluid flow over a stretching sheet. The above mentioned studies investigated the viscoelastic nanofluid flow problems in the absence of elastic deformation effect.

Hence, in the present article we investigated the elastic deformation effects on the boundary layer flow of an incompressible second grade nanofluid model over a stretching surface in the presence of suction and

\footnotetext{
"Corresponding author. Email: abdulhakeem6@gmail.com
} 
partial slip boundary condition. The second grade nanofluid is carefully model with Brownian motion, elastic deformation and thermophoresis effects. The heat and mass flux boundary conditions are used to analyze the heat and mass transfer of the second grade nanofluid. The nondimensional governing equations are numerical solved by fourth order Runge-Kutta method together with shooting method.

\section{MATHEMATICAL FORMULATION}

We consider two-dimensional, steady, laminar and incompressible of viscoelastic nanofluid flow through a continuously stretching sheet with slip boundary condition. The velocity of the stretching sheet is $u_{w}=U=a x$, where $a>0$ is constant (acceleration parameter). The flow is assumed to be in the $x$-direction, which is chosen along the sheet and the $y$-axis perpendicular to it (see Fig. 1). The surface of sheet is maintained at uniform temperature $T_{w}$ and solid volume friction of nanofluid $C_{w}$ and these values are assumed to be greater than the ambient temperature $T_{\infty}$ and solid volume friction of nanofluid $C_{\infty}$. Thermally equilibrium state is considered, and the external force and pressure gradient are neglected The boundary layer equations for the flow, heat and concentration fields under the above assumption are (Goyal and Bhargava 2013) :

$u_{x}+v_{y}=0$

$u u_{x}+v u_{y}=\vartheta u_{y y}+k_{0}\left\{u u_{x y y}+v u_{y y y}+u_{x} u_{y y}-u_{y} u_{x y}\right\}$

$u T_{x}+v T_{y}=\frac{k}{\rho C_{p}} T_{y y}+\frac{\delta k_{0}}{C_{p}}\left\{u_{y}\left(u u_{x}+v u_{y}\right)\right\}$

$$
+\tau\left\{D_{B} T_{y} C_{y}+\frac{D_{T}}{T_{\infty}}\left(T_{y}\right)^{2}\right\}
$$

$u C_{x}+v C_{y}=D_{B} C_{y y}+\frac{D_{T}}{T_{\infty}} T_{y y}$

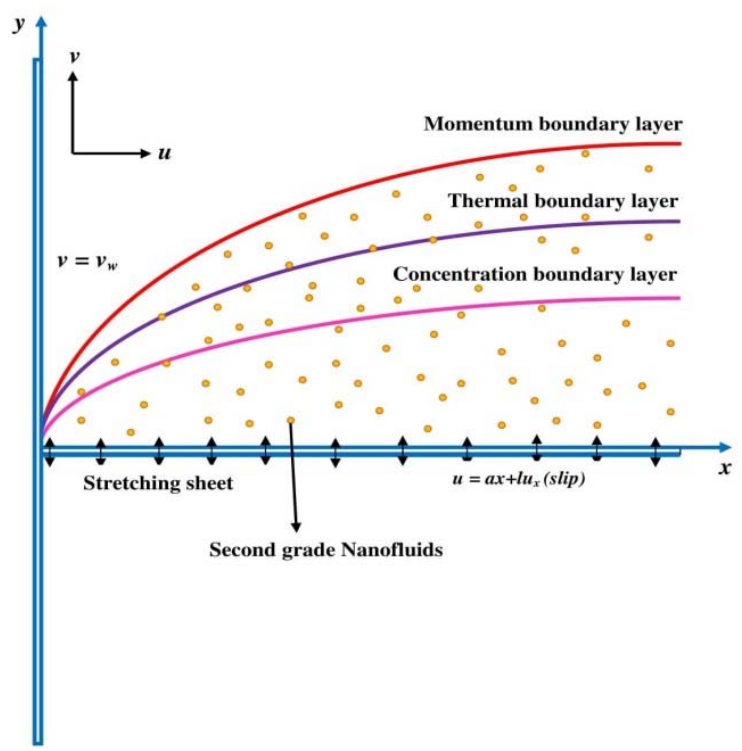

Fig. 1 Physical model of the problem.

Where $k_{0}$ is the elastic parameter, $\rho$ is the density, $k$ is the thermal conductivity, $C_{p}$ is the specific heat of constant pressure, $\vartheta$ is the kinematic viscosity, $\delta$ is the coefficient of elastic deformation term
( $\delta$ is introduced to make out the contribution of elastic deformation to the heat transfer), $\tau$ is the ratio of effective heat capacity of nanoparticle material to heat capacity of the base fluid, $D_{B}$ is the Brownian diffusion coefficient and $D_{T}$ is the thermophoresis diffusion coefficient.

To facilitate the investigation, we introduce the following similarity transformations and dimensionless variables $\eta$ and $f_{\eta}$ as

$$
u=\operatorname{axf}_{\eta}(\eta), \quad v=(a \vartheta)^{1 / 2} f(\eta) \text { and } \quad \eta=\left(\frac{a}{\vartheta}\right)^{1 / 2} y
$$

The boundary conditions of Eqs. (2)-(4) are as follow

$u=a x+l u_{x}, \quad v=v_{w}$ at $\quad y=0$

$-k \frac{\partial T}{\partial y}=q_{w}=E_{1}\left(\frac{x}{l}\right)^{2}$ (Heat flux) at $y=0$

$-D \frac{\partial T}{\partial y}=h_{w}=E_{2}\left(\frac{x}{l}\right)^{2}$ (Mass flux) at $y=0$

$u \rightarrow 0, \quad T \rightarrow T_{\infty}, \quad C \rightarrow C_{\infty} \quad$ as $\quad y \rightarrow \infty$

Where $E_{1}, E_{2}$ are constants and $l$ is the characteristic length. We now define a dimensionless, scaled temperature $\theta(\eta)$ and concentration $\phi(\eta)$ are

$$
\theta(\eta)=\frac{T-T_{\infty}}{T_{w}-T_{\infty}}, \quad \phi(\eta)=\frac{C-C_{\infty}}{C_{w}-C_{\infty}}
$$

Using the similarity transformation (5), the governing momentum, energy and concentration equations can be expressed in non-dimensional form under the above assumptions as

$$
\begin{gathered}
f_{\eta \eta \eta}+f f_{\eta \eta}-f_{\eta}^{2}+k_{1}\left(2 f_{\eta} f_{\eta \eta \eta}-f f_{\eta \eta \eta \eta}-f_{\eta \eta}^{2}\right)=0 \\
\theta_{\eta \eta}+\operatorname{Pr} f \theta_{\eta}-2 \operatorname{Pr} f_{\eta} \theta+\delta k_{1} E c \operatorname{Pr} f_{\eta \eta}\left(f_{\eta} f_{\eta \eta}-f f_{\eta \eta \eta}\right) \\
+N b \operatorname{Pr} \theta_{\eta} \phi_{\eta}+N t \operatorname{Pr} \theta_{\eta}^{2}=0 \\
\phi_{\eta \eta}-2 L e f_{\eta} \phi+L e f \phi_{\eta}+\frac{N t}{N b} \theta_{\eta \eta}=0
\end{gathered}
$$

The corresponding non-dimensional velocity slip, heat flux and mass flux boundary conditions are

$$
\begin{aligned}
& f(0)=s, \quad f_{\eta}(0)=1+L f_{\eta \eta}(0), \quad f_{\eta}(\infty)=0 \text { and } f_{\eta \eta}(\infty)=0 \\
& \theta_{\eta}(0)=-1 \text { and } \theta(\infty)=0 \\
& \phi_{\eta}(0)=-1 \text { and } \phi(\infty)=0
\end{aligned}
$$

where the subscript $\eta$ denotes differentiation with respect to $\eta$, $k_{1}=\frac{k_{0} a}{\vartheta}$ is the viscoelastic parameter, $L=l \sqrt{\frac{a}{\vartheta}}$ is the slip parameter, $\operatorname{Pr}=\frac{\mu C_{p}}{k}$ is the Prandtl number, $E c=\frac{u_{w}^{2}}{C_{p}\left(T_{w}-T_{\infty}\right)}$ is the Eckert number, $N b=\frac{\tau D_{B}\left(C_{w}-C_{\infty}\right)}{\vartheta}$ is the Brownian motion parameter, $N t=\frac{\tau D_{T}\left(T_{w}-T_{\infty}\right)}{T_{\infty} \vartheta}$ is the thermophoresis parameter, $L e=\frac{\vartheta}{D_{B}}$ is the Lewis number.

The physical quantities of interest are the local skin friction coefficient, the local Nusselt number and the local Sherwood number which are defined as

$$
C_{f}=\frac{\tau_{w}}{\frac{1}{2} \rho u_{w}^{2}}=2 \operatorname{Re}_{x}^{-1 / 2}\left(1+3 k_{1}\right) f_{\eta \eta}(0)
$$




$$
\begin{aligned}
& T_{w}=T_{\infty}+\frac{q_{w}}{k} \sqrt{\frac{\vartheta}{a}} \theta(0) \\
& C_{w}=C_{\infty}+\frac{h_{w}}{D} \sqrt{\frac{\vartheta}{a}} \phi(0) \\
& \text { where } \quad \tau_{w}=\left\lfloor\vartheta u_{y}+k_{0}\left(u u_{x y}+2 u_{x} u_{y}\right)\right]_{y=0}
\end{aligned}
$$

\section{VALIDATION OF THE NUMERICAL SOLUTION}

Employing the R.K method with shooting technique to the nondimensional ODE's along with boundary conditions, the numerical solution are obtained for different set of parameters. The validation of the obtained numerical results are assured by comparing the skin friction coefficient values in the absence of slip parameter with Cortell (2006) for ordinary second grade fluid which is presented in Table 1 . We have compared the results of $\theta(0)$ with those of Turkyilmazoglu (2011) in the absence of slip parameter, viscoelastic parameter, suction parameter, Eckert number, Lewis number, Brownian motion parameter and Thermophoresis parameter. The comparison is found to be in excellent agreement as shown in Table 2.

\section{RESULTS AND DISCUSSION}

\subsection{Results for second grade nanofluid velocity, temperature and solid volume fraction profiles}

The effects of various physical parameters on velocity, temperature and solid volume fraction of second grade nanofluid profiles for stretching surface have been shown graphically in Figs. 2-9. The combined effects of viscoelastic parameter with slip and suction parameters on the second grade nanofluid velocity profile are shown in Figs. 2 and 3. It is noted that an increase in the viscoelastic parameter resulted in an increase in the horizontal velocity profile of the second grade nanofluid. It is observed from Fig. 2, an increment in the slip parameter decelerates the velocity profile. When slip occurs, the second grade nanofluid flow velocity near the sheet is no longer equal to the stretching velocity of the sheet. With the increase in slip parameter, such slip velocity increases and consequently second grade nanofluid velocity decreases because under the slip condition, the pulling of the stretching sheet can be only partly transmitted to the second grade nanofluid. An opposite trend has been observed for suction parameter from Fig. 3 .

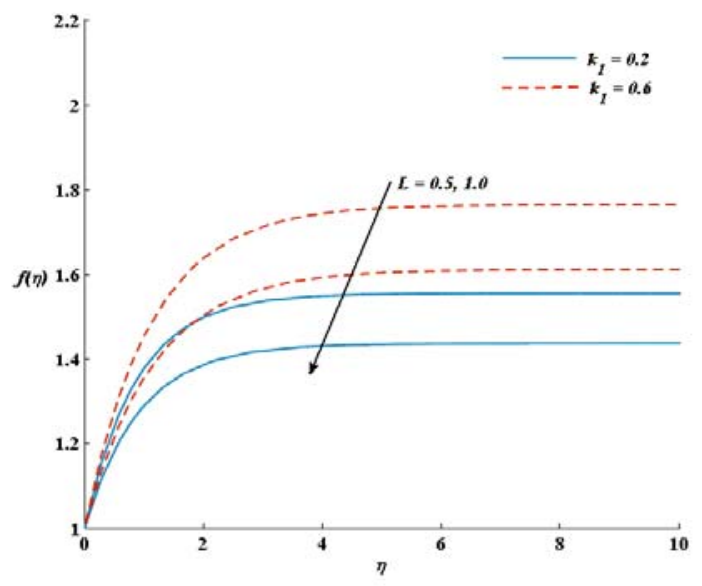

Fig. 2 Effects of slip and viscoelastic parameters on velocity profile $f(\eta)$ with $s=1$.

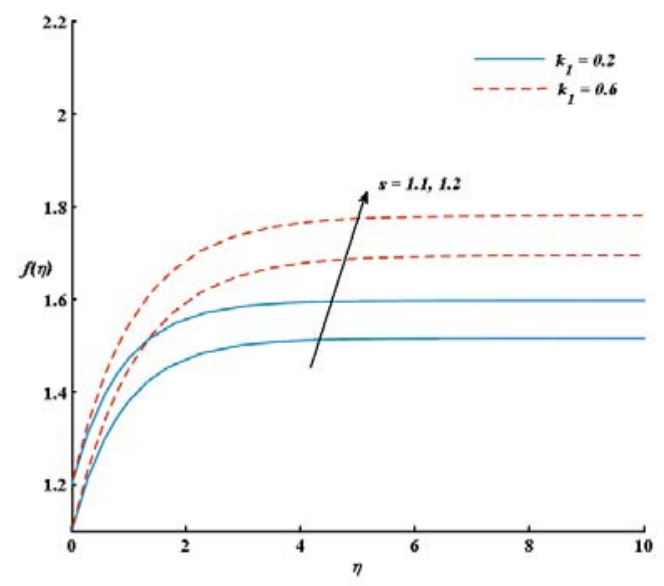

Fig. 3 Effects of suction and viscoelastic parameters on velocity profile $f(\eta)$ with $L=1$.

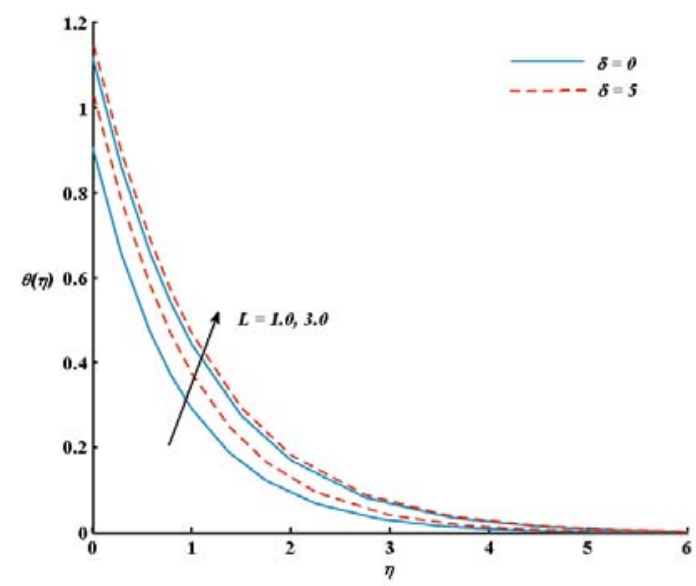

Fig. 4(a) Effects of slip and elastic deformation parameters on temperature profile $\theta(\eta)$ with $s=1, k_{l}=0.6, \operatorname{Pr}=0.71$, $E c=0.5, L e=2, N b=0.3$ and $N t=0.3$.

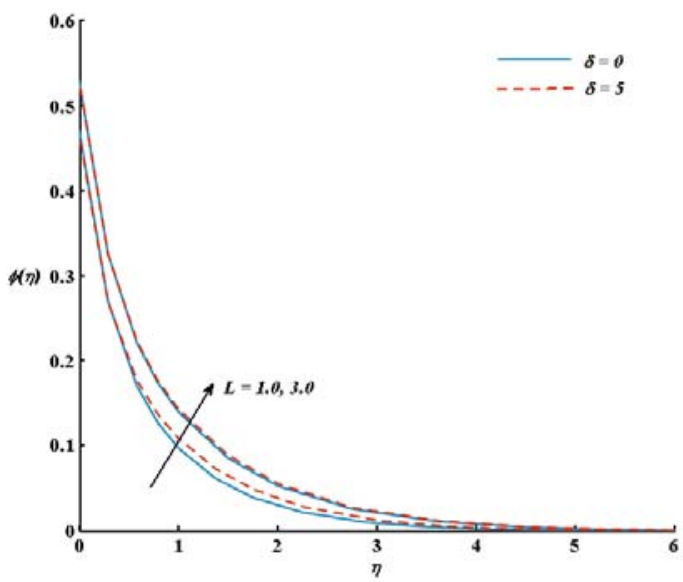

Fig. 4(b) Effects of slip and elastic deformation parameters on concentration profile $\phi(\eta)$ with $s=1, k_{1}=0.6, \operatorname{Pr}=0.71$, $E c=0.5, L e=2, N b=0.3$ and $N t=0.3$. 


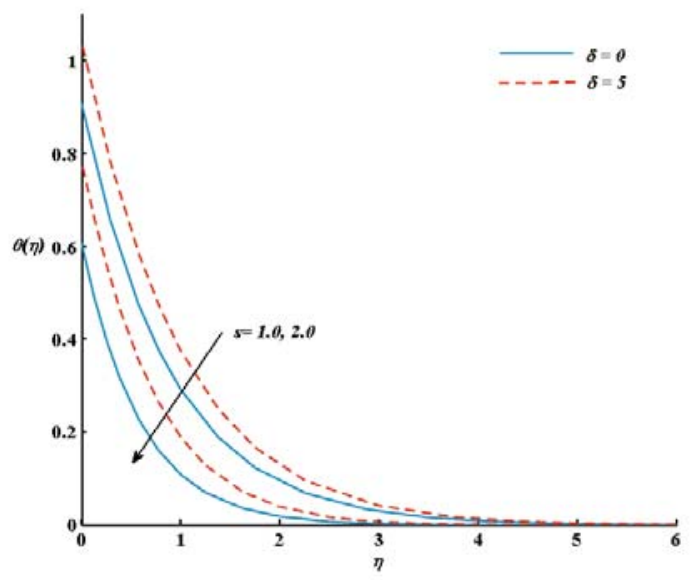

Fig. 5(a) Effects of suction and elastic deformation parameters on temperature profile $\theta(\eta)$ with $L=1, k_{l}=0.6, \operatorname{Pr}=0.71$, $E c=0.5, L e=2, N b=0.3$ and $N t=0.3$.

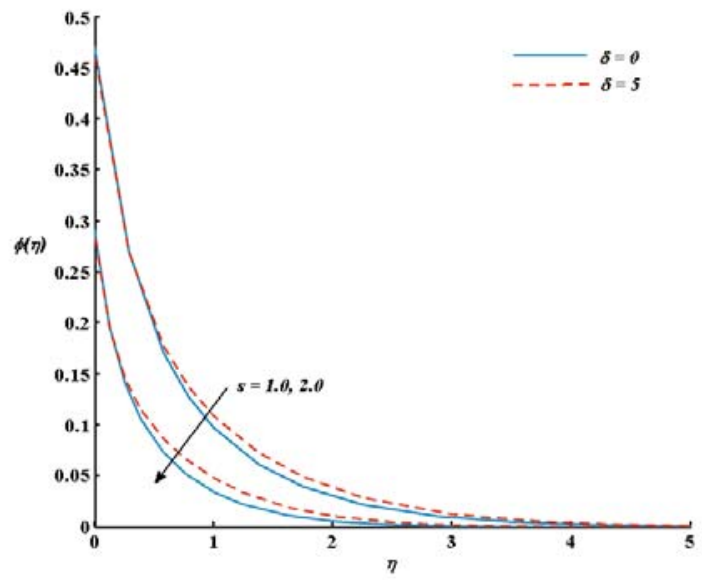

Fig. 5(b) Effects of suction and elastic deformation parameters on concentration profile $\phi(\eta)$ with $L=1, k_{l}=0.6, P r=0.71$, $E c=0.5, L e=2, N b=0.3$ and $N t=0.3$.

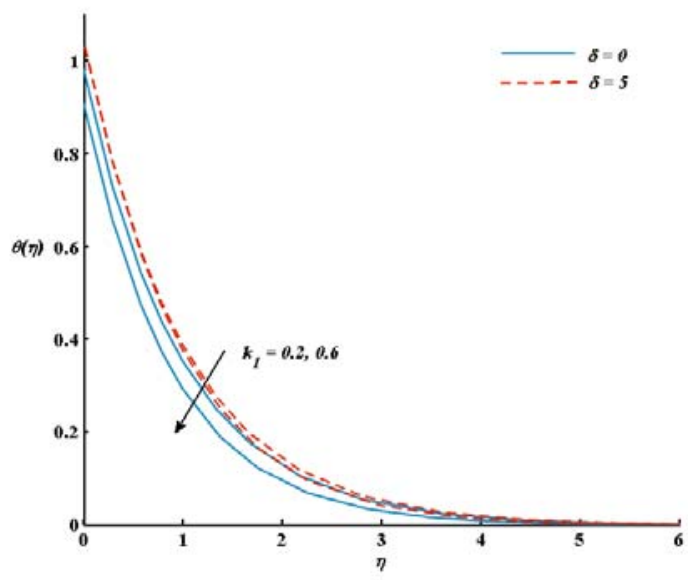

Fig. 6(a) Effects of viscoelastic and elastic deformation parameters on temperature profile $\theta(\eta)$ with $L=1, s=1, \operatorname{Pr}=0.71, E c=0.5$, $L e=2, N b=0.3$ and $N t=0.3$.

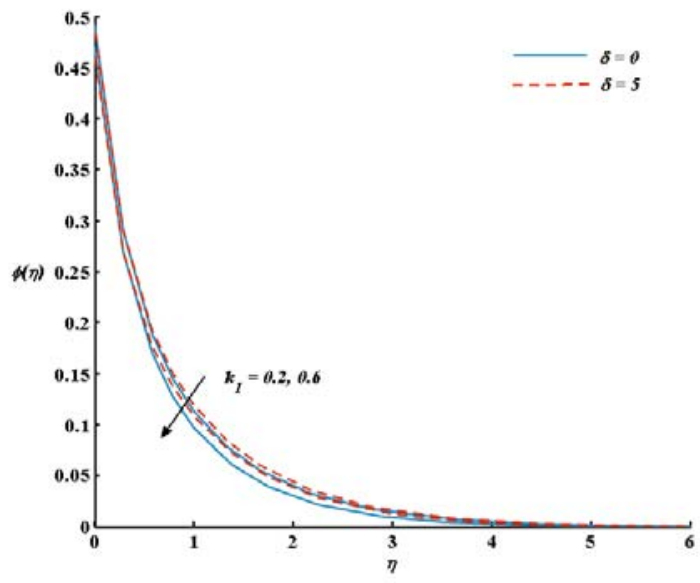

Fig. 6(b) Effects of viscoelastic and elastic deformation parameters on concentration profile $\phi(\eta)$ with $L=1, s=1, \operatorname{Pr}=0.71, E c=0.5$, $L e=2, N b=0.3$ and $N t=0.3$.

The effect of slip parameter on the temperature and solid volume fraction of the second grade nanofluid in the presence and in the absence of elastic deformation parameter is depicted in Fig. 4. It is noted that an increment in the slip parameter in the presence of elastic deformation parameter increases both the temperature and solid volume fraction of nanofluid profiles (Figs. 4 (a) and 4(b) ). It is interesting to note that from Fig. 4(b), the combined effect of slip and elastic deformation parameter does not a show a significant effect on nanofluid solid volume fraction profile near the wall, but a notable effect can be seen far away from the wall. It may be concluded that the presence of elastic deformation parameter increases the thickness of both the second grade nanofluid thermal and concentration boundary layers.

The variation of temperature and solid volume fraction profiles of second grade nanofluid with suction and elastic deformation parameters are illustrated in Fig. 5. It is clear that the suction parameter decreases both the temperature and solid volume fraction of second grade nanofluid boundary layers. Suction parameter shows an opposing effect on temperature and solid volume fraction of nanofluid profiles compared to slip parameter. It may be concluded that the effects of slip velocity parameter on temperature and solid volume fraction of nanofluid profiles can be controlled by increasing the suction of the second grade nanofluid in the stretching sheet. The effect viscoelastic parameter with elastic deformation parameter on the second grade nanofluid temperature and solid volume fraction of nanofluid profiles are shown in Fig. 6. It is observed that the temperature and solid volume fraction of nanofluid profiles decrease with viscoelastic parameter.

The influences of Brownian motion and thermophoresis parameters with elastic deformation parameter on the temperature and solid volume fraction of nanofluid profiles are displayed in Figs. 7 and 8, respectively. The Brownian motion parameter helps to measure the strength of the Brownian diffusion of the nanoparticles in the flow field. It is found that the second grade nanofluid temperature profile enhances as the Brownian motion of the particles increases and an opposite effect on the nanoparticle volume fraction within the second grade nanofluid boundary layer region (Fig. 7 (b)). Due to the collision of small nanoparticles in the flow field, a thermal energy is generated which enhances the second grade fluid temperature. Due to the Brownian diffusion, the nanoparticles tend to move away from the surface of the sheet and as result a decrease in nanoparticle volume fraction is encountered within the boundary layer region. It is observed from Fig. 8 , the thermal and solid volume fraction of nanofluid profiles enhance with thermophoresis parameter in the presence of elastic deformation parameter.

The effect of Lewis number with elastic deformation parameter on second grade nanofluid temperature and solid volume fraction of 
nanofluid profiles is shown in Fig. 9. It can be seen that an increment in Lewis number decreases both the temperature and solid volume fraction of nanofluid profiles. This is probably due to the fact that mass transfer rate of second grade nanofluid increases as Lewis number increases. It also reveals that the concentration gradient at surface of the stretching sheet increases. Moreover, the concentration at the surface of stretching sheet decreases as Lewis number increases.

\subsection{Results for skin friction coefficient, local Nusselt number and local Sherwood number}

Fig. 10 demonstrates the effect of suction, slip and viscoelastic parameters on the local skin friction coefficient of second grade nanofluid. The viscoelastic parameter is taken as $x$-axis and $f_{\eta \eta}(0)$ is taken as $y$-axis. It can be seen that the increase of suction and viscoelastic parameters enhances the skin friction coefficient and the slip parameter diminishes skin friction coefficient.

The effect of elastic deformation parameter with various physical parameters on the local Nusselt number and local Sherwood number is depicted in Figs. 11 - 12. In these figures, elastic deformation parameter is taken as $x$-axis and the corresponding local Nusselt number $\theta(0)$ (Figure captions with subscript (a)) and the local Sherwood number $\phi(0)$ (Figure captions with subscript (b)) are taken as $y$-axis. Figs. 11(a) and 11(b) show the effect of Prandtl, Eckert, Lewis numbers with elastic deformation parameters on local Nusselt number and local Sherwood number of second grade nanofluid. The increase of Lewis number decreases both local Nusselt number and local Sherwood number. It is noted that the increase of Prandtl number decreases the local Nusselt number (Fig. 11(a)) and increases the local Sherwood number (Fig. 11(b)) and the Eckert number shows an opposite effect.

The effects of thermophoresis, Brownian motion with elastic deformation parameters on local Nusselt number and local Sherwood number are illustrated in Figs. 12(a) and 12(b) respectively. It is observed that the increase of Brownian motion parameter increases the local Nusselt number and decreases the local Sherwood number. It is also noted that the increase of thermophoresis parameter increases the local Nusselt number and local Sherwood number.

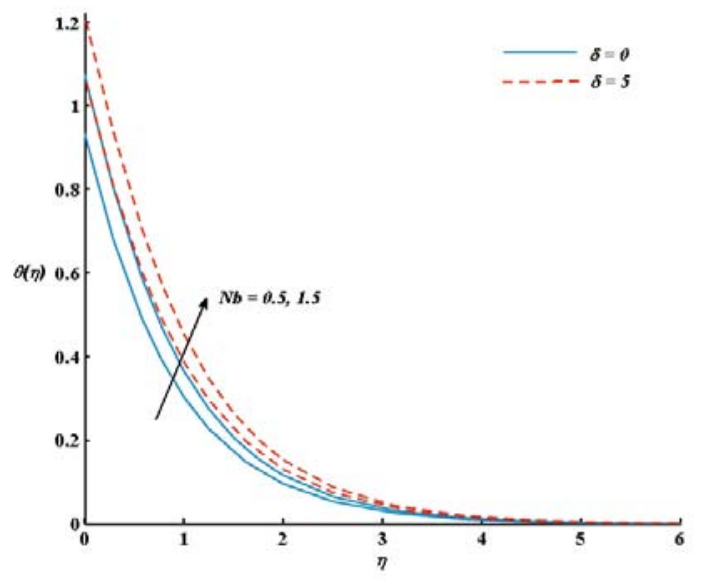

Fig. 7(a) Effects of Brownian motion and elastic deformation parameters on temperature profile $\theta(\eta)$ with $L=1, s=1$, $k_{1}=0.6, P r=0.71, L e=2, \quad E c=0.5$ and $N t=0.3$.

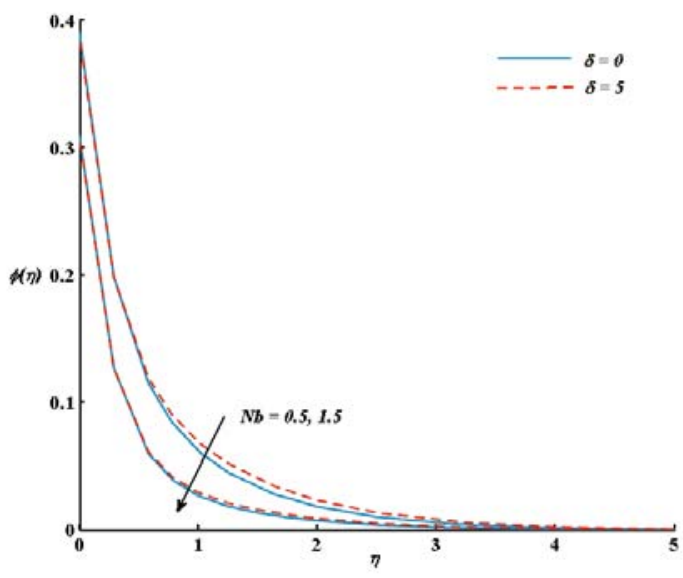

Fig. 7(b) Effects of Brownian motion and elastic deformation parameters on concentration profile $\phi(\eta)$ with $L=1, s=1$, $k_{1}=0.6, \operatorname{Pr}=0.71, L e=2, E c=0.5$ and $N t=0.3$.

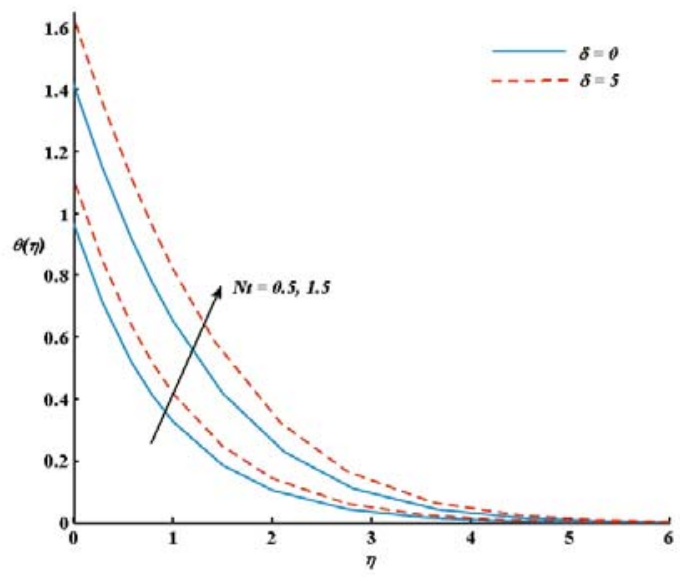

Fig. 8(a) Effects of thermophoresis and elastic deformation parameters on temperature profile $\theta(\eta)$ with $L=1, s=1$, $k_{1}=0.6, \operatorname{Pr}=0.71, L e=2, E c=0.5$ and $N b=0.3$.

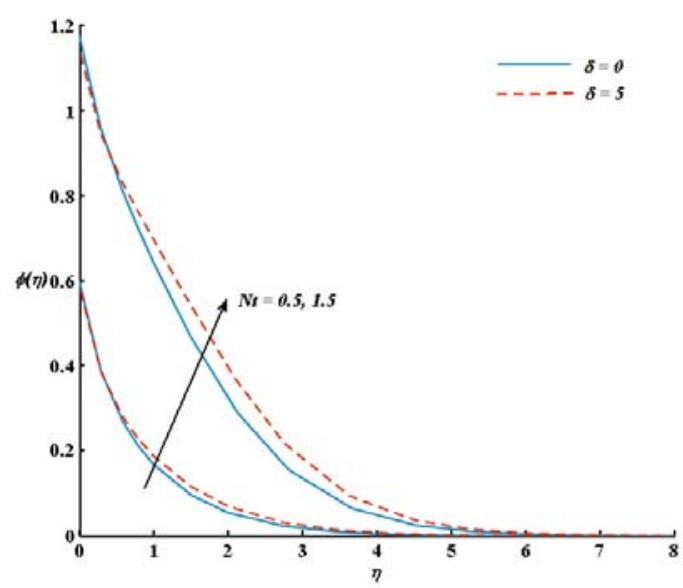

Fig. 8(b) Effects of thermophoresis and elastic deformation parameters on concentration profile $\phi(\eta)$ with $L=1, s=1$, $k_{l}=0.6, \operatorname{Pr}=0.71, L e=2, E c=0.5$ and $N b=0.3$. 


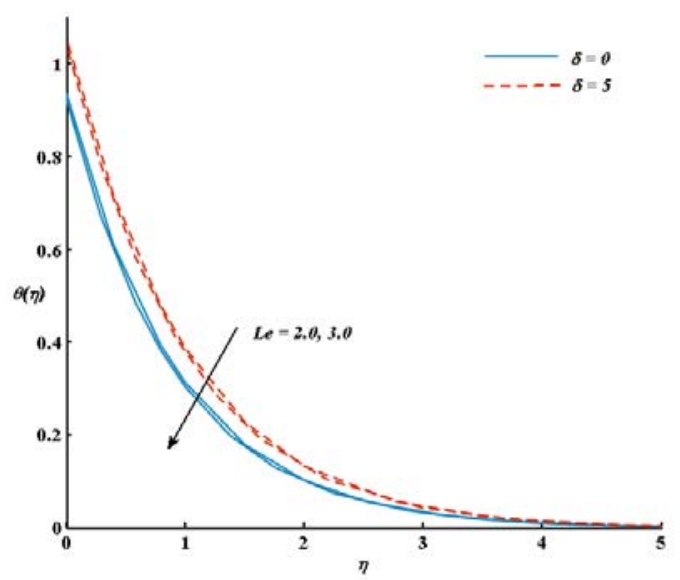

Fig. 9(a) Effects of Lewis number and elastic deformation parameter on temperature profile $\theta(\eta)$ with $L=1, s=1$, $k_{1}=0.6, \operatorname{Pr}=0.71, E c=0.5, N t=0.3$ and $N b=0.3$

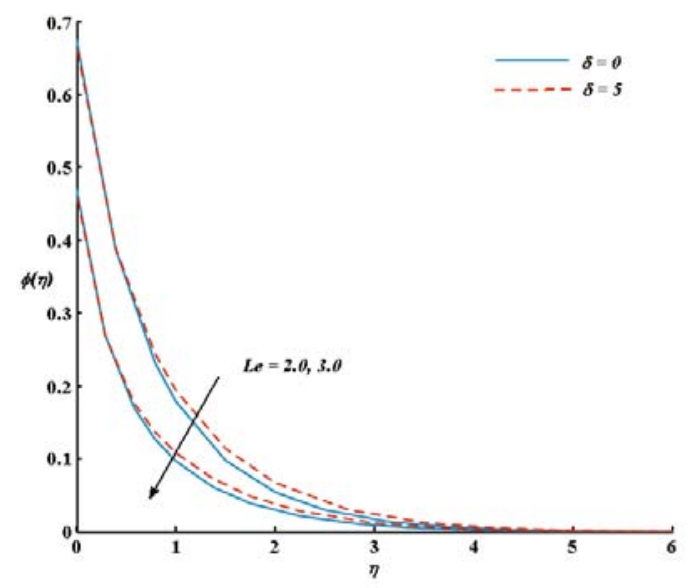

Fig. 9(b) Effects of Lewis number and elastic deformation parameter on concentration profile $\phi(\eta)$ with $L=1, s=1$, $k_{1}=0.6, P r=0.71, E c=0.5, N t=0.3$ and $N b=0.3$

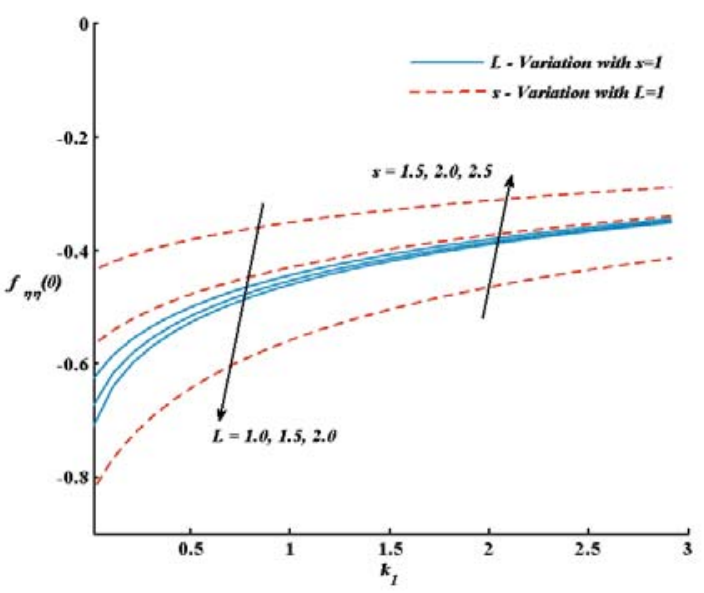

Fig. 10 Effects of slip, suction parameters and viscoelastic parameter on local skin friction $f_{\eta \eta}(0)$

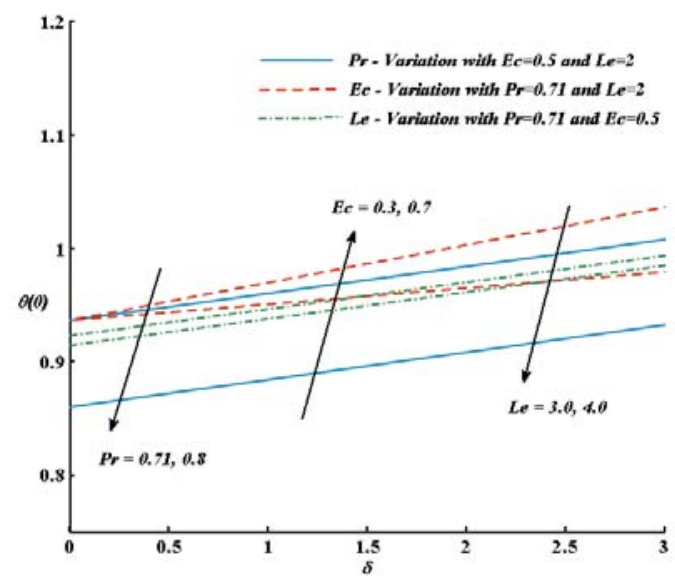

Fig. 11(a) Effects of Prandtl, Eckert, Lewis numbers and elastic deformation parameters on local Nusselt number $\Theta(0)$ with $L=1, s=1, k_{1}=0.6, N t=0.3$ and $N b=0.3$.

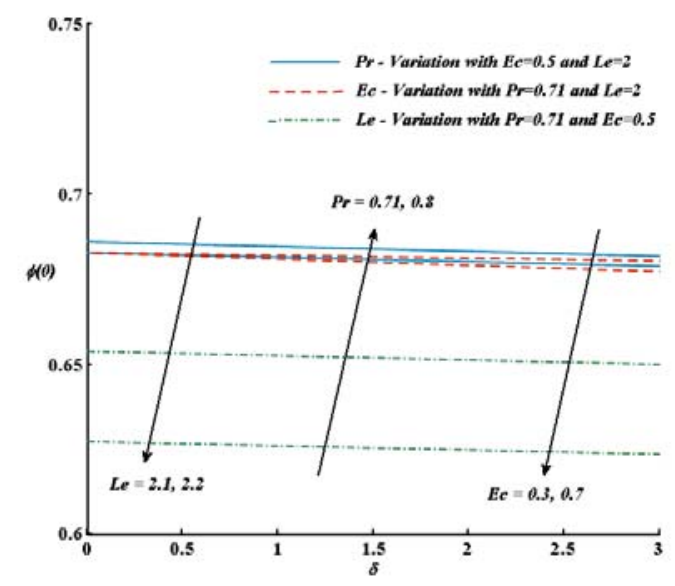

Fig. 11(b) Effects of Prandtl, Eckert, Lewis numbers and elastic deformation parameters on local Sherwood number $\phi(0)$ with $L=1, s=1, k_{1}=0.6, N t=0.3$ and $N b=0.3$.

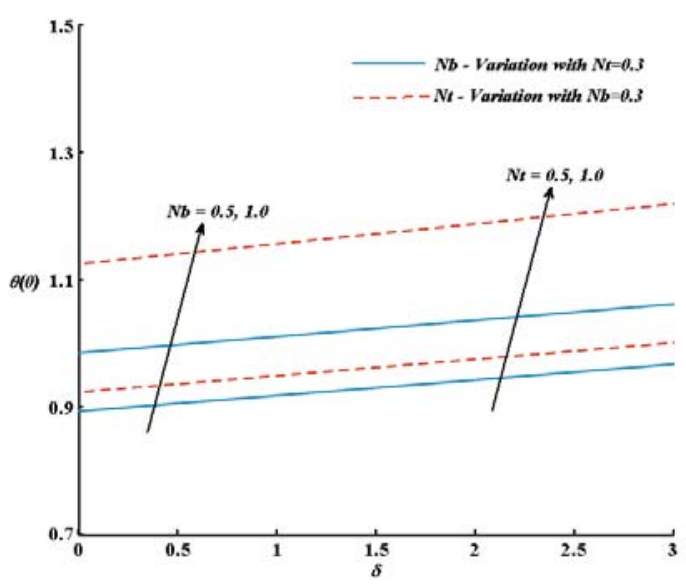

Fig. 12(a) Effects of thermophoresis, Brownian motion and elastic deformation parameters on local Nusselt number $\Theta(0)$ with $L=1, s=1, k_{1}=0.6, \operatorname{Pr}=0.71, E c=0.5$ and $L e=2$. 


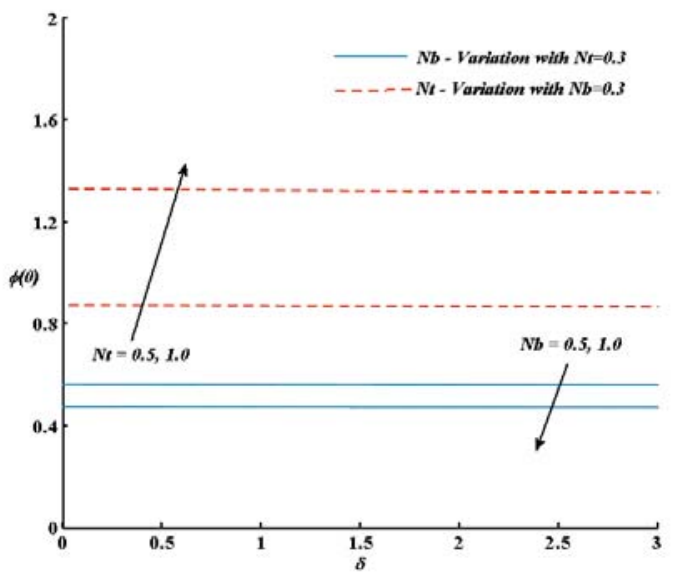

Fig. 12(b) Effects of thermophoresis, Brownian motion and elastic deformation parameters on local Sherwood number $\phi(0)$ with $L=1, s=1, k_{1}=0.6, \operatorname{Pr}=0.71, E c=0.5$ and $L e=2.0$.

Table 1. Comparison values of skin friction $\left(-f_{\eta \eta}(0)\right)$

\begin{tabular}{|c|c|c|c|}
\hline \multicolumn{2}{|c|}{$L=0$} & \multicolumn{2}{|c|}{$-f_{\eta \eta}(0)$} \\
\cline { 1 - 1 } $\boldsymbol{k}_{1}$ & \multirow{2}{*}{$\boldsymbol{s}$} & $\begin{array}{c}\text { Cortell } \\
(2006)\end{array}$ & $\begin{array}{c}\text { Present } \\
\text { results }\end{array}$ \\
\cline { 4 - 4 } & & 0.801988 & 0.80193774 \\
1 & 1 & 0.618084 & 0.61803400 \\
2 & 1 & 0.854688 & 0.85463768 \\
1 & 2 & 0.921257 & 0.92120754 \\
1 & 5 & \multicolumn{2}{|c}{} \\
\hline
\end{tabular}

Table 2. Comparison values of Nusselt number $(\Theta(0))$

\begin{tabular}{|c|c|c|}
\hline $\begin{array}{c}\boldsymbol{L}=\boldsymbol{s}=\boldsymbol{k}_{1}={ }_{\delta}=\boldsymbol{0} \\
\boldsymbol{E} \boldsymbol{c}=\boldsymbol{L} \boldsymbol{e}=\boldsymbol{0},\end{array}$ & \multicolumn{2}{|c|}{$\boldsymbol{\theta}(\mathbf{0})$} \\
\hline $\operatorname{Pr}$ & $\begin{array}{c}\text { Turkyilmazoglu } \\
\text { (2011) }\end{array}$ & Present results \\
\hline 1 & 0.75000 & 0.75000 \\
\hline 5 & ---------- & 0.30152 \\
\hline
\end{tabular}

\section{CONCLUSION}

The influences of elastic deformation effects on second grade nanofluid flow over a stretching sheet with suction and velocity slip is investigated numerically. The governing nonlinear ordinary differential equations of the flow and heat transfer problem are solved numerically by the fourth order Runge-Kutta method with shooting iteration technique. Some of the important findings drawn from the present investigation are listed as follow

- The presence of elastic deformation parameter increases the thickness of the second grade nanofluid thermal and concentration boundary layers.

- The velocity profile and skin friction coefficient decrease with the increasing values of slip parameter and increase with suction and viscoelastic parameters.
- The increasing values of elastic deformation parameter, Eckert number, Brownian motion and thermophoresis parameters increase the temperature and local Nusselt number of the nanofluid. The local Nusselt number decreases whenever Lewis number and Prandtl number increase.

- The solid volume fraction of nanofluid profile and local Sherwood number enhance with the increasing values thermophoresis parameter and Prandtl number, and reduce with elastic deformation parameter, Eckert number and Lewis number.

- The presence of elastic deformation plays vital role in controlling the thermal and concentration boundarylayer thickness.

- The effects of slip velocity parameter on temperature and solid volume fraction profiles can be controlled by increasing the suction of the second grade nanofluid in the stretching sheet.

\section{NOMENCLATURE}

C solid volume friction

$C_{w} \quad$ solid volume friction of the sheet

$C_{\infty} \quad$ solid volume friction far away from the sheet

$C_{f} \quad$ Local skin friction coefficient (Pascal)

$c_{p} \quad$ specific heat of constant pressure $(\mathrm{J} / \mathrm{kg} \mathrm{K})$

$D \quad$ molecular diffusivity $\left(\mathrm{m}^{2} / \mathrm{s}\right)$

$D_{B} \quad$ Brownian diffusion coefficient $\left(\mathrm{m}^{2} / \mathrm{s}\right)$

$D_{T} \quad$ the thermophoresis diffusion coefficient $\left(\mathrm{m}^{2} / \mathrm{s}\right)$

Ec Eckert number

$k$ thermal conductivity $(\mathrm{W} / \mathrm{m} \mathrm{K})$

$k_{0} \quad$ the elastic parameter

$k_{I} \quad$ viscoelastic parameter

$L \quad$ slip parameter

Le Lewis number

$l \quad$ the characteristic length $(\mathrm{m})$

$\mathrm{Nb} \quad$ Brownian motion parameter

Nt thermophoresis parameter

$\mathrm{Pr} \quad$ Prandtl number

$\operatorname{Rex}^{1 / 2} \quad$ Reynolds number

$T \quad$ local temperature of the fluid (K)

$T_{w} \quad$ temperature of the sheet (K)

$T_{\infty} \quad$ temperature of the fluid far away from the sheet $(\mathrm{K})$

$u, v \quad$ velocity component in $x$ and $y$ direction $(\mathrm{m} / \mathrm{s})$

$x, y \quad$ coordinates along and perpendicular to the sheet $(\mathrm{m})$

\section{Greek symbols}

$\delta \quad$ elastic deformation

$\sigma \quad$ electric conductivity $(\mathrm{S} / \mathrm{m})$

$\rho$ density $\left(\mathrm{kg} / \mathrm{m}^{3}\right)$

$\theta \quad$ dimensionless temperature

$\phi \quad$ dimensionless concentration

$\eta \quad$ dimensionless space variable

$\vartheta$ the kinematic viscosity $\left(\mathrm{m}^{2} / \mathrm{sec}\right)$

$\tau \quad$ the ratio of effective heat capacity of nanoparticle material to heat capacity of the base fluid $(\mathrm{J} / \mathrm{K})$

$\tau_{w} \quad$ wall shearing stress $\left(\mathrm{N} / \mathrm{m}^{2}\right)$

\section{Acknowledgement}

The authors wish to express his sincere thanks to the honorable referees and the editor for their valuable comments and suggestions to improve the quality of the paper. One of the author (A.K. A. H) gratefully acknowledges the financial support of UGC, New Delhi, India UGC/SERO/MRP-22 6729/16 for pursuing this work. 


\section{REFERENCES}

Abdul Hakeem, A.K., Vishnu Ganesh, N., Ganga, B., 2015, "Magnetic Field Effect on Second Order Slip Flow of Nanofluid Over a Stretching/Shrinking Sheet with Thermal Radiation Effect," Journal of Magnetism and Magnetic Materials, 381, 243-257. https://doi.org/10.1016/i.jmmm.2014.12.010

Abolbashari, M.H., Freidoonimehr, N., Nazari, F., Rashidi, M.M., 2014, "Entropy Analysis for an Unsteady MHD Flow Past a Stretching Permeable Surface in Nanofluid," Powder Technology., 267, 256-267.

https://doi.org/10.1016/j.powtec.2014.07.028.

Buongiorno, J., 2005, "Convective Transport in Nanofluids," Journal of Heat Transfer, 128(3), 240-250. https://doi.org/10.1115/1.2150834.

Choi, S.U.S., 1995, “ Enhancing Thermal Conductivity of Fluids with Nanoparticles, Developments and Applications of NonNewtonian Flows," ASME: Fluids Engineering Division, 231, 99 105.

Cortell, R., 2006, "Effects of Viscous Dissipation and Work Done by Deformation on the MHD Flow and Heat Transfer of a Viscoelastic Fluid over a Stretching Sheet," Physics Letters A, 357, 298-305. https://doi.org/10.1016/j.physleta.2006.04.051.

Govindraju, M., Ganga, B., Abdul Hakeem, A.K., 2017, "Second Law Analysis on Radiative Slip Flow of Nanofluid Over a Stretching Sheet in the Presence of Lorentz Force and Heat Generation/Absorption," Frontiers in Heat and Mass Transfer, 8, 1-8. https://doi.org/10.5098/hmt.8.10.

Goyal, M., Bhargava, R., 2013, "Numerical Solution of MHD Viscoelastic Nanofluid Flow over a Stretching Sheet with Partial Slip and Heat Source/Sink," ISRN Nanotechnology, Article ID 931021,

http://dx.doi.org/10.1155/2013/931021.

Goyal, M., Bhargava, R., 2014, "Boundary Layer Flow and Heat Transfer of Viscoelastic Nanofluid Past a Stretching Sheet with Partial Slip Condition," Applied Nanoscience., 4, 761-767. https://doi.org/10.1007/s13204-013-0254-5.

Rashidi, M.M,, Vishnu Ganesh, N., Abdul Hakeem, A.K., Ganga, B., 2014, "Buoyancy Effect on MHD Flow of Nanofluid Over a Stretching Sheet in the Presence of Thermal Radiation," Journal of Molecular Liquids, $\quad$ 198, 234-238. https://doi.org/10.1016/i.molliq.2014.06.037.

Sheikholeslami, M., Rashidi, M.M., 2015, "Effect of Space Dependent Magnetic Field on Free Convection of Fe3O4-Water Nanofluid," Journal of the Taiwan Institute of Chemical Engineers, 56, 6-15.

https://doi.org/10.1016/j.jtice.2015.03.035

Sheikholeslami, M., Rashidi, M.M., Ganji, D.D., 2015, "Effect of Non-Uniform Magnetic Field on Forced Convection Heat Transfer of $\mathrm{Fe}_{3} \mathrm{O}_{4}$-Water Nanofluid, Computer Methods in Applied
Mechanics and Engineering, 294, 299-312. https://doi.org/10.1016/j.cma.2015.06.010.

Sheikholeslami, M., Rokni, H.B., 2017a, "Simulation of Nanofluid Heat Transfer in Presence of Magnetic field: A Review," International Journal of Heat and Mass Transfer, 115, 1203-1233.

https://doi.org/10.1016/j.ijheatmasstransfer.2017.08.108.

Sheikholeslami, M., 2017a, "Numerical Simulation of Magnetic Nanofluid Natural Convection in Porous Media," Physics Letters A, 381, 494-503.

https://doi.org/10.1016/j.physleta.2016.11.042.

Sheikholeslami, M., 2017b, "Influence of Lorentz Forces on Nanofluid Flow in a Porous Cylinder Considering Darcy Model," Journal of Molecular Liquids, 225, 903-912. https://doi.org/10.1016/j.molliq.2016.11.022.

Sheikholeslami, M., 2017c, "Influence of Coulomb Forces on $\mathrm{Fe}_{3} \mathrm{O}_{4}-\mathrm{H}_{2} \mathrm{O}$ Nanofluid Thermal Improvement, International Journal of Hydrogen Energy, 42, 821-829.

https://doi.org/10.1016/j.ijhydene.2016.09.185.

Sheikholeslami, M., 2014, “ Effect of Spatially Variable Magnetic Field on Ferrofluid Flow and Heat Transfer Considering Constant Heat Flux Boundary Condition," The European Physical Journal Plus, 129- 248. https://doi.org/10.1140/epjp/i2014-14248-2.

Sheikholeslami, M., 2017d, "Lattice Boltzmann Method Simulation for MHD Non-Darcy Nanofluid Free Convection," Physica B 516, $55-71$.

https://doi.org/10.1016/j.physb.2017.04.029.

Sheikholeslami, M., 2017e, "Magnetic Field Influence on $\mathrm{CuO}$ H2O Nanofluid Convective Flow in a Permeable Cavity Considering Various Shapes for Nanoparticles," International Journal of Hydrogen Energy, 42, 19611-19621.

https://doi.org/10.1016/i.ijhydene.2017.06.121

Sheikholeslami, M., Rokni, H. B., 2017b, “ Nanofluid two Phase Model Analysis in Existence of Induced Magnetic Field," International Journal of Heat and Mass Transfer, 107, 288-299. https://doi.org/10.1016/j.ijheatmasstransfer.2016.10.130

Sheikholeslami, M., Bhatti, M.M. 2017, “Active Method for Nanofluid Heat Transfer Enhancement by Means of EHD," International Journal of Heat and Mass Transfer, 109, 115-122. https://doi.org/10.1016/j.ijheatmasstransfer.2017.01.115

Sheikholeslami, M., Shehzad, S.A., 2017a, “ Thermal Radiation of Ferrofluid in Existence of Lorentz Forces Considering Variable Viscosity," International Journal of Heat and Mass Transfer, 109, 82-92. https://doi.org/10.1016/j.ijheatmasstransfer.2017.01.096

Sheikholeslami, M., Hayat, T., Alsaedi, A., 2017a, “ Numerical Simulation of Nanofluid Forced Convection Heat Transfer Improvement in Existence of Magnetic Field Using Lattice Boltzmann Method," International Journal of Heat and Mass Transfer, 108, 1870-1883.

https://doi.org/10.1016/j.ijheatmasstransfer.2017.01.044. 
Sheikholeslami, M., Shamlooei, M., 2017, " $\mathrm{Fe}_{3} \mathrm{O}_{4}-\mathrm{H}_{2} \mathrm{O}$ Nanofluid Natural Convection in Presence of Thermal Radiation," International Journal of Hydrogen Energy, 42(9) , 5708-5718. https://doi.org/10.1016/j.ijhydene.2017.02.031.

Sheikholeslami, M., Shehzad, S.A., 2017b, "Magneto Hydrodynamic Nanofluid Convection in a Porous Enclosure Considering Heat Flux Boundary Condition," International Journal of Heat and Mass Transfer , 106, 1261-1269. https://doi.org/10.1016/j.ijheatmasstransfer.2016.10.107.

Sheikholeslami, M., Hayat, T., Alsaedi, A., 2017b, "Numerical Study for External Magnetic Source Influence on Water Based Nanofluid Convective Heat Transfer," International Journal of
Heat and Mass Transfer, 106, 745-755.

https://doi.org/10.1016/i.ijheatmasstransfer.2016.09.077.

Shi,t G.C., Halder, R., Ghosh, S.K., 2016, "Convective Heat Transfer and MHD Viscoelastic Nanofluid Flow Induced by Stretching Sheet," International Journal of Applied and Computational Mathematics, 2(4), 593-608.

https://doi.org/10.1007/s40819-015-0080-4.

Turkyilmazoglu, M., 2011, “Analytic Heat and Mass Transfer of the Mixed Hydrodynamic/Thermal Slip MHD Viscous Flow Over a Stretching Sheet," International Journal of Mechanical Sciences. 53, 886-896.

https://doi.org/10.1016/j.ijmecsci.2011.07.012. 